九州大学学術情報リポジトリ

Kyushu University Institutional Repository

\title{
Delayed Light Emission as a Means of Automatic Sorting of Tomatoes
}

Chuma, Yutaka

Laboratory of Agricultural Process Engineering, Faculty of Agriculture, Kyushu University

Nakaji, Ke i

Laboratory of Agricultural Process Engineering, Faculty of Agriculture, Kyushu University

Tagawa, Akio

Laboratory of Agricultural Process Engineering, Faculty of Agriculture, Kyushu University

https://doi.org/10.5109/23752

出版情報: 九州大学大学院農学研究院紀要. 26 (4)，pp.221-234，1982-07. Kyushu University バージョン：

権利関係 : 
J. Fac. Agr.. Kyushu Univ., 26(4), 221-234 (1982)

\title{
Delayed Light Emission as a Means of Automatic Sorting of Tomatoes
}

\author{
Yutaka Chuma, Kei Nakaji and Akio Tagawa \\ Laboratory of Agricultural Process Engineering, Faculty of \\ Agriculture, Kyushu University 46-05, Fukuoka 812
}

(Received March 11, 1982)

\begin{abstract}
DLE characteristics for tomatoes were investigated to obtain the basic data for the color sorting. The investigated factors concerned with the DLE characteristics were 'dark period', exciting illuminance and time, exciting area, fruit's temperature, chlorophyll content and excited depth of tomato flesh.
\end{abstract}

\section{INTRODUCTION}

Color development of tomatoes is mainly related to the decrease of chlorophyll and the increase of carotenoid or Iycopin with its maturity. If the stages of color development of tomatoes were related to the content of chlorophyll, a useful way for a mechanical sorting of tomatoes could be expected. On this occasion, non-destructive and rapid evaluation of all tomatoes in the processing line are needed.

The characteristics of delayed light emission of tomatoes were investigated to obtain the basic data for the color sorting.

\section{MEASURING APPARATUS OF DLE INTENSITY}

A schematic diagram of experimental apparatus is shown in Fig. 1. The apparatus consists of (1) an optical unit, (2) an electrical unit, (3) a recording unit and (4) a measuring and controlling unit of tomato temperature.

\section{An optical unit}

White light from light source (tungsten lamp, LS) passes through a lens (L1), a filter of neutral density ( $F$ 1), a shutter (SH) and a lens (L2) and is reflected toward a sample by movable mirror (M), which hinged at the lower end, shuts the light path on closing the shutter and opens the light path of DLE.

The delayed light, emitted from the sample, passes through an interference filter (F 2), a sharp cut filter (F3) and a condenser lens (L 3), then is conveyed to photomultiplier tube (PMT). The interior wall of the light path and dark chamber are painted with nonluminescent black lacquer to absorb the scattering light.

A constant voltage transformer was used for the tungsten lamp. To 


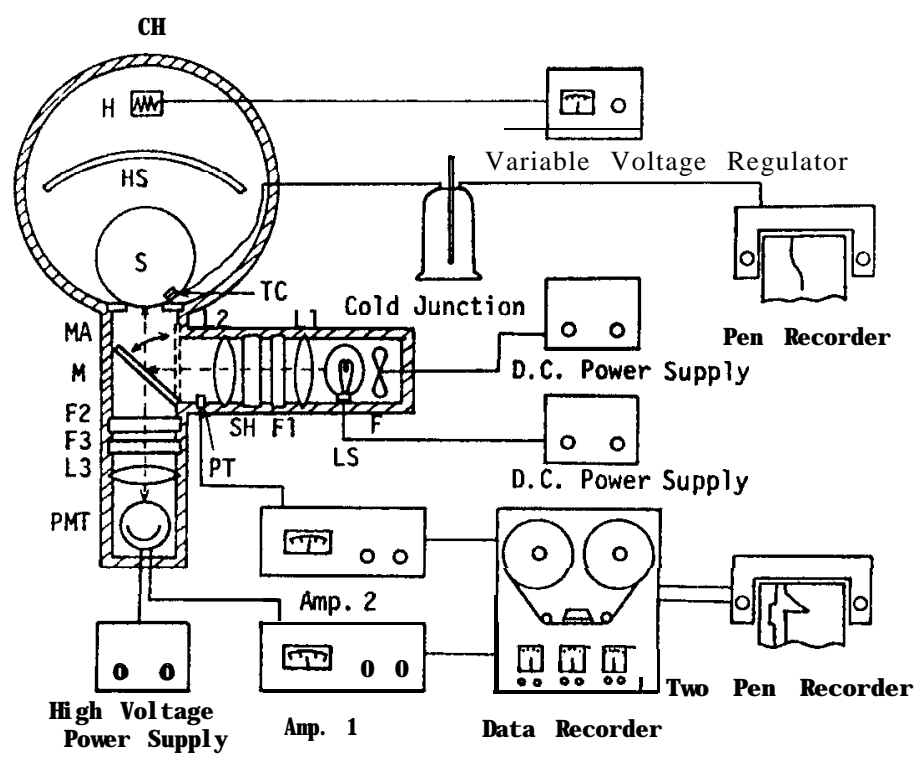

Fig. 1. Schematic diagram of experimental apparatus for detecting DLE intensity. CH: dark chamber; H: heater; HS: heat shield; S: sample; F: fan; LS: light source (tungsten lamp); L1, L2, L3: lens; SH: shutter; M: mirror; F1: ND filter; F2: interference filter; F3: UV filter; PMT: photomultiplier tube ; PT: phototransister ; TC: thermocouple ; MA : mask.

obtain the stability for the long run test, the voltage and current were regulated to 90 percent of the rated values, 12 volts and 4 amperes, and the lamp was cooled by a fan. The filters of ND-Z, ND-4 and ND-8 (made by Kenko Co. Inc.) located in $F 1$ were used to regulate the amount of exciting light. Each of the filters has the uniform transmittance properties in visible regions. The exciting area of the sample was determined by the opening of the window mask (MS), the maximum opening being $9.07 \mathrm{~cm}^{2}$.

For measuring the DLE spectrum interference filter $F 2$ and sharp cut filter F 3 were inserted into the light-path of the DLE. The interference filter from 403.3 to $781.0 \mathrm{~nm}, \mathrm{KL}-40 \sim 78$ (Toshiba Kasei Co. Ltd.), and the sharp cut filter, UV-39 type (Toshiba Kasei) was used.

\section{Electrical and recording unit}

Photomultiplier tube (PMT). R-270 (Hamamatsu TV), was connected with high voltage power supplier of 660volt. The photoelectric current due to the DLE was led into a data-recorder passing by an amplifier (1). A phototransistor (PT) excited by light source during the excitation generated a signal, which was fed into a data-recorder passing by an amplifier (2). Two signals of the DLE and excitation period were plotted into a two-pen recorder, the time dimension being expanded by 10 times.

\section{Fruit temperature}

The temperature of the tomatoes was changed by electric heater $(H)$ in 
the dark chamber. The temperature was controlled by variable voltage regulator. Heat shield (HS) was used for the uniformity of heat distribution on the surface of tomato. The temperature of the tomatoes was measured by thermocouple (TC) inserted $1 \mathrm{~mm}$ beneath the surface, and recorded by pen recorder.

\section{EXPERIMENTAL METHOD}

\section{Materials}

Tomatoes, (Taibyo Hokan No. 2), were obtained from a local farm in Munakata district in Fukuoka Prefecture from mid-July to the end of August in 1975 .

\section{Measurement of DLE intensity}

Tomatoes from the farm were kept at room temperature. Prior to the DLE measurement the apparatus was stabilized by supplying the current for the period of 30 minutes. The DLE was measured at the periphery of blossom end, the exciting area being $9.07 \mathrm{~cm}^{2}$.

Procedure is as follows:

(1) The tomato was located into the dark chamber for 20 minutes to lower the intensity of DLE due to the previous ambient excitation under the circumstances, followed by the pre-illumination for 60 seconds, returned to dark chamber conditions for a required period of time, and then excited by illumination.

(2) The DLE signal recorded into data-recorder by the tape speed of $152.4 \mathrm{~cm}$ per second (60ips) was regenerated by the tape speed of $15.24 \mathrm{~cm}$ per second (6ips), hence the time scale was extended by ten times. Thus the relation between the decay period and the DLE intensity was obtained.

\section{Measurement of exciting illuminance on tomato}

Exciting illuminance of $5,500 \mathrm{~lx}$ was used in all measurements except for the special case. The illuminance was measured by illuminometer (Toshiba Electric., No. 5 type). The relationship between exciting illuminance and DLE intensity was investigated using the regulated excitation from 172 to 5,500 Ix by neutral density filter.

\section{Determination of chlorophyll}

The procedure for the chlorophyll determination was based on the absorption of light by aqueous acetone (80percent) extracts of chlorophyll, (Mac. kinney, 1941). The flesh specimen of $6 \mathrm{~mm}$ thick and $28 \mathrm{~mm}$ dia. $\left(3.68 \mathrm{~cm}^{3}\right)$ was taken from the outer layer of tomatoes. Absorbancies (A) of the extracted chlorophyll solution were measured with a spectrophotometer at 645 and $663 \mathrm{~nm}$, and the content of chlorophyll $\mathrm{a}$ and $\mathrm{b}$ was calculated from the following simultaneous equations, 


$$
\begin{aligned}
& \text { Chl. a: } \quad x=12.72 \quad A_{663}-2.59 A_{645}, \\
& \text { Chl. b: } \quad \mathrm{x}=22.88 \quad A,,--4.67 \quad A_{663} .
\end{aligned}
$$

$x$ : contents (milligrams) of chlorophyll a or b per liter of the extracted chlorophyll solution $(\mathrm{mg} / \mathrm{l})$.

Total chlorophyll content $(\mathrm{mg} / \mathrm{l})$ is

$$
\text { Chl. }(\mathrm{a}+\mathrm{b}): \quad x=20.29 A_{645}+8.05 A_{663} \text {. }
$$

In this experiment, total chlorophyll content was in $\mu \mathrm{g} / \mathrm{cm}^{3}$ units.

$$
x^{\prime}=x \times \frac{V}{1000} \times \frac{1000}{3.69} .
$$

$x^{\prime}$ : contents (micrograms) of chlorophyll a plus b per milliliter of the extracted chlorophyll solution $\left(\mu \mathrm{g} / \mathrm{cm}^{3}\right), V$ : volume of aqueous acetone (80 percent) extracts of chlorophyll (ml). Hence,

$$
x^{\prime}=0.271 V \cdot x
$$

\section{Color groups of tomatoes}

The tomatoes were classified into four color groups from green to red, independent of size and shape, by two panelists (Table 1).

Table 1. Color groups of tomatoes.

\begin{tabular}{clc}
\hline Color group & \multicolumn{1}{c}{ External color } & Number \\
\hline 1 & Green, green to trace yellow & \\
2 & Greenish yellow and light pink & 17 \\
3 & Orange and light red (no green) & 20 \\
4 & Red, deep red & 20 \\
\hline
\end{tabular}

\section{RESULTS AND DISCUSSION}

\section{Dark recovery}

Fig. 2 shows the decay curves of DLE for green tomatoes. The initial value of DLE intensity was higher under the longer dark period. The dark periods prior to the excitation had much effect on the initial part of DLE curves. Nevertheless, the curves overlapped mutually several seconds' later at points $\mathrm{P}_{1}$ and $\mathrm{P}_{2}$ as shown in Fig. 2 .

The dark recovery of DLE for green tomatoes is clearly shown in Fig. 3 in terms of decay periods. Dark recovery means the point of curve where the DLE intensity becomes independent of 'dark period'. Five minutes of 'dark period' results in the 'dark recovery' at point a under the 'decay period' of 1.0 second. Under the 'decay period' longer than 1.2 seconds the DLE intensity was stabilized independent of the 'dark period'.

From these results, the dark period of 10 minutes and the decay period 


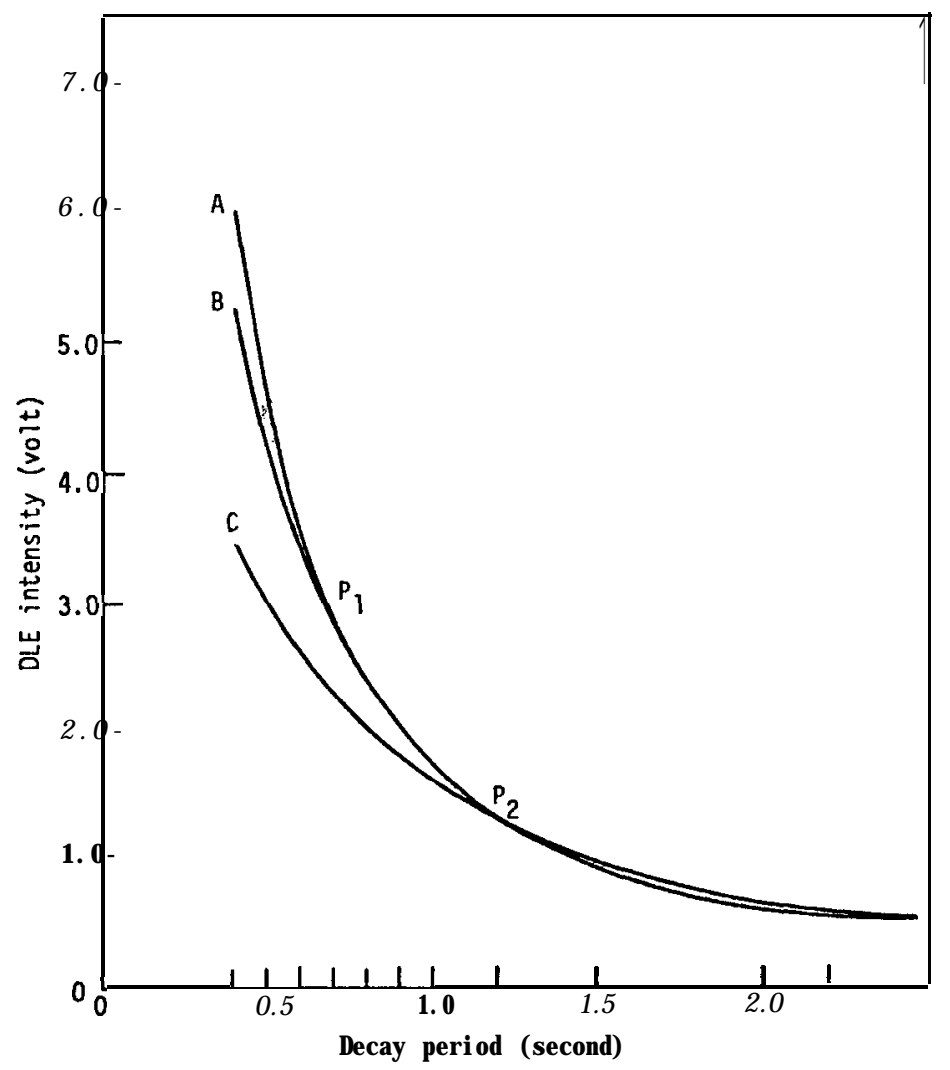

Fig. 2. Decay curves of DLE intensity for green tomatoes. Conditions: pre-illumination time $60 \mathrm{sec}$. exciting illumination time $4 \mathrm{sec}$, illuminance $5,5001 \mathrm{x}$, illumination area $9.07 \mathrm{~cm}^{2}$, temperature $31^{\circ} \mathrm{C}$. A: dark period 20 min, B: dark period $10 \mathrm{~min}, \mathrm{C}$ : dark period $0 \mathrm{~min}$. Point of dark recovery: $P_{1}, P$,

of 0.7 seconds were used for the measurement of the DLE intensity.

The possible separation of the time of excitation and DLE measurement offers several conveniences for designation and installation of the sorting machine by DLE and leads to the simplification of the sorting mechanism.

\section{Effect of excitation time on DLE intensity}

Effect of exciting time on DLE intensity is shown in Fig. 4. The maximum DLE was obtained for the excitation from 3 to 6 seconds, and additional excitation beyond that seemed to decrease the DLE intensity.

Excitation time of 60 seconds resulted in a steady level of DLE intensity. The preillumination time of 60 seconds taken for the experiment of 'dark recovery', was necessary to obtain the initial uniform condition of the DLE.

\section{Effect of exciting light intensity on DLE}

Fig. 5 shows the effect of exciting light intensity on DLE for green toma- 


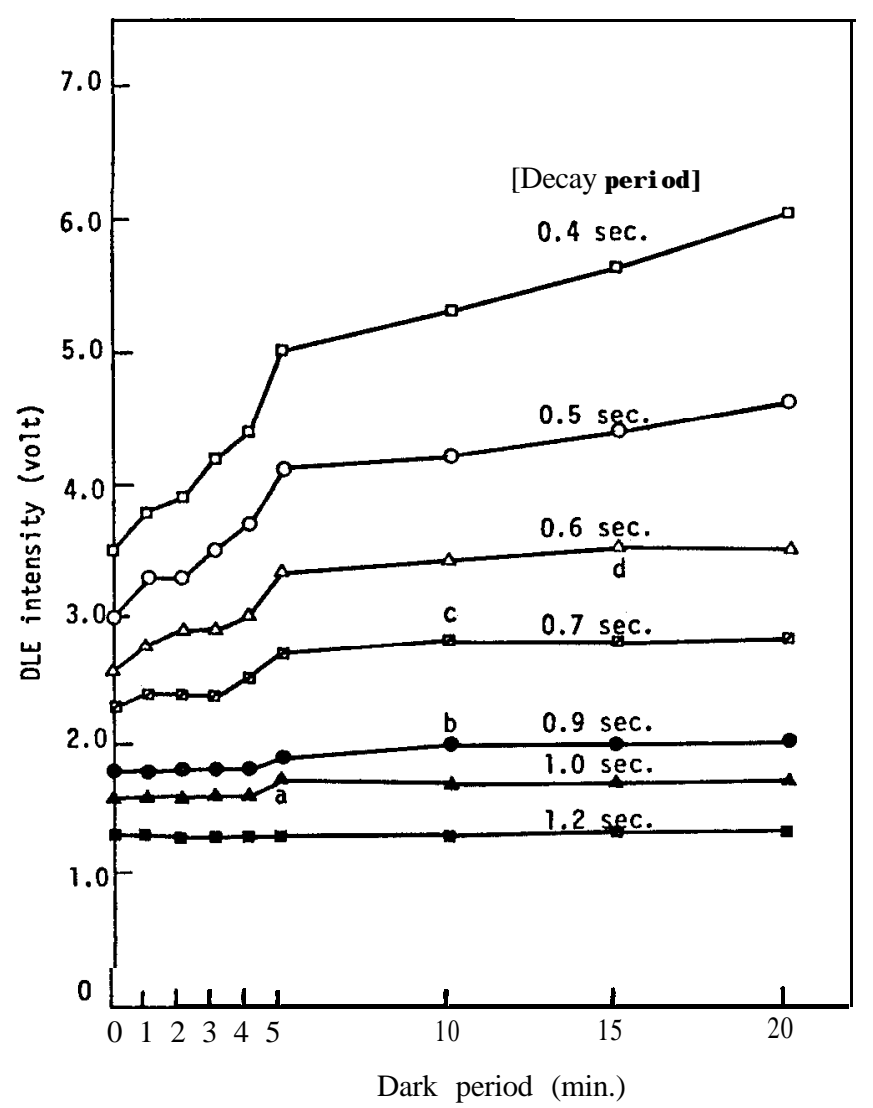

Fig. 3. Dark recovery of DLE for green tomatoes.

toes. The chlorophyll in tomatoes was excited by a feeble illumination of $172 \mathrm{~lx}$ for 4 seconds and emitted delayed light.

The illuminances needed for the DLE saturation were 5,500, 2,750 and $1,375 \mathrm{~lx}$ under the decay period of $0.7,1.0$ and 1.2 seconds respectively. Broad choice and design of exciting light are permitted beyond the range of saturation of DLE.

\section{Effect of excitation area on DLE intensity}

Fig. 6 shows the effect of excitation area on DLE intensity for green tomatoes. The excitation area was the same as the emission area.

The DLE intensity was directly proportional to the excitation area.

\section{Effect of flesh temperature on DLE intensity}

Fig. 7 shows the effect of flesh temperature of green tomatoes on DLE intensity. The DLE increased with the rise of temperature from 8 to $13^{\circ} \mathrm{C}$, followed by a wide peak between 13 to $17^{\circ} \mathrm{C}$, then decreased gradually with rising temperature reaching to a half of the maximum DLE at $41^{\circ} \mathrm{C}$. 


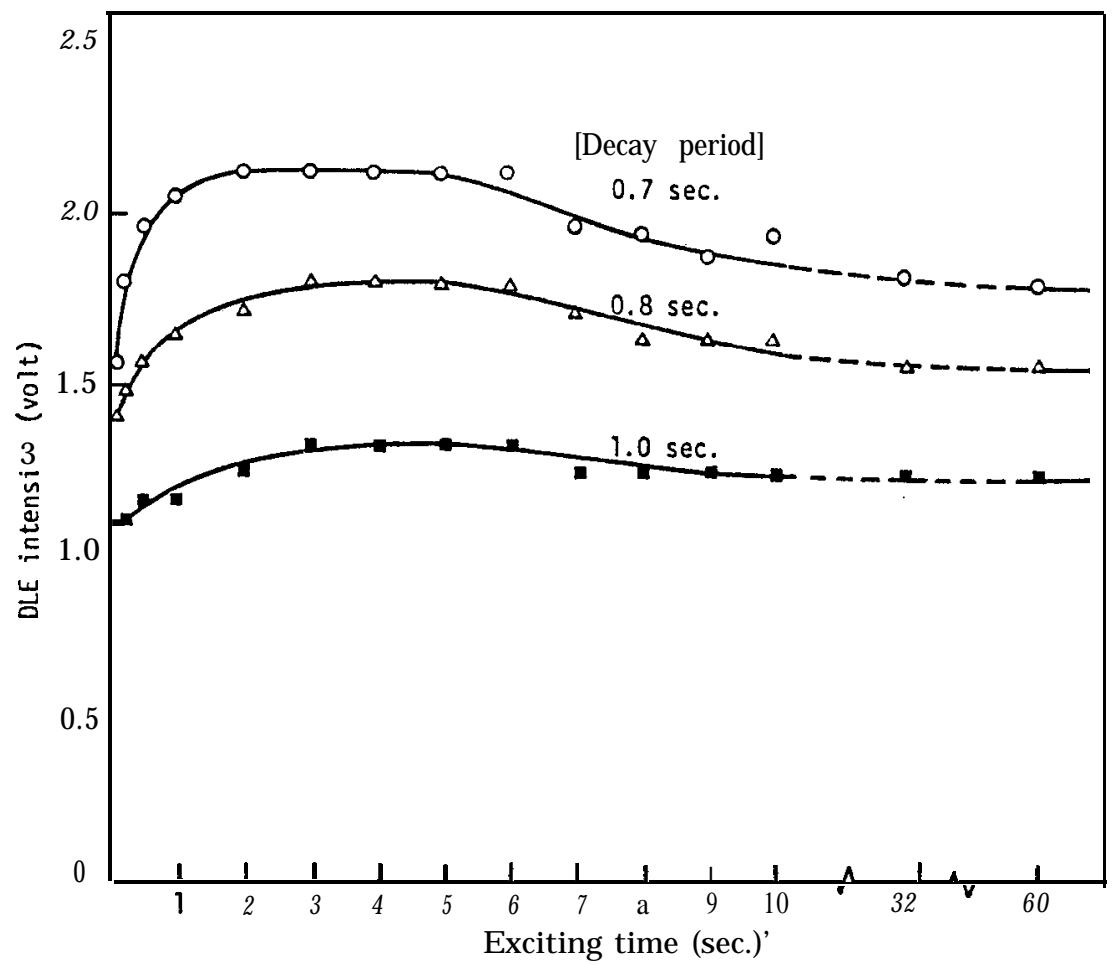

Fig. 4. Effect of exciting time on DLE intensity for green tomatoes. Conditions : dark period $10 \mathrm{~min}$, illuminance 5,500 Ix, illumination area 9.07 $\mathrm{cm}^{2}$, temperature $31^{\circ} \mathrm{C}$.

These results differed from other plant materials. DLE intensity of chlorophyll in oranges decreased inversely with the rise of fruit temperature from 1 to $38^{\circ} \mathrm{C}$ (Jacob et al., 1965), that of chlorella had a peak at $37^{\circ} \mathrm{C}$ (Strehler and Arnold, 1951), and that of Satsuma orange showed a peak at $31^{\circ} \mathrm{C}$ then followed by decrease with rise in fruit temperature reaching zero beyond $41^{\circ} \mathrm{C}$ (Chuma et al., 1977). Adequate storage temperature of green tomatoes is from 13 to $21^{\circ} \mathrm{C}$ (ASHRAE, 1971), and at this temperature high intensity of DLE is obtained, which is entirely favorable for practical sorting.

\section{Relationship between chlorophyll content and DLE intensity}

The relationship between chlorophyll content in tomato and DLE intensity is shown in Fig. 8. The following regression was obtained for the decay period of 0.7 seconds.

$$
y=0.163 x+0.298 \quad r=0.916
$$

$\mathrm{y}$ : DLE intensity (output volt), $\mathrm{x}$ : chlorophyll content $\left(\mu \mathrm{g} / \mathrm{cm}^{3}\right), r$ : correlation coefficient.

The correlation coefficient was statistically significant at 0.1 percent level. 


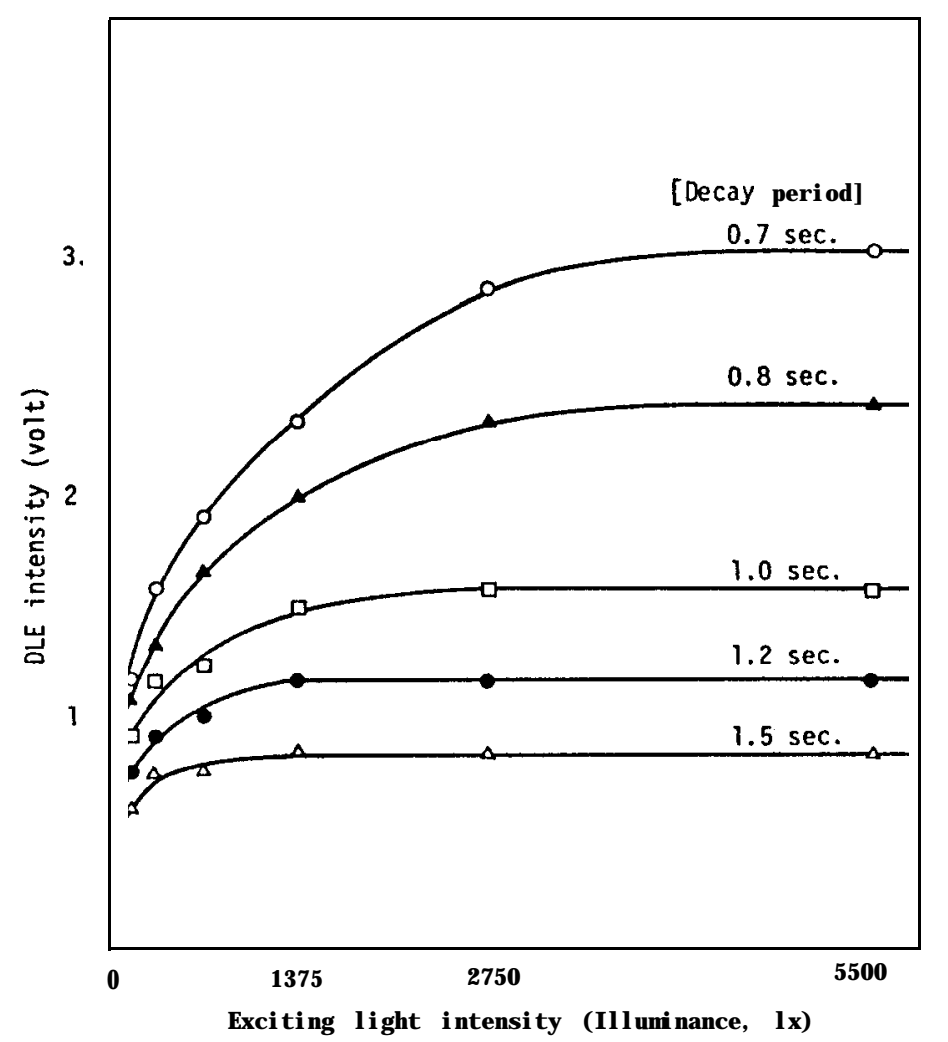

Fig. 5. Effect of exciting light intensity on DLE for green tomatoes. Conditions: dark period $10 \mathrm{~min}$, exciting illumination time $4 \mathrm{sec}$, illumination area $9.07 \mathrm{~cm}^{2}$, temperature $33^{\circ} \mathrm{C}$.

Hence, the delayed light emission can be used for measuring chlorophyll concentration, which leads to maturity evaluation of tomatoes.

\section{Color sorting accuracy of tomato by DLE intensity}

Tomatoes classified manually into four color groups from green (color group 1) to matured red (color group 4) were mixed and used as test samples. The samples were sorted by means of DLE intensity. Experimental conditions were as follows. Number of tomatoes: 77, dark period: 10 minutes, excitation : 5,500 lx for 4 seconds, excitation area: $9.07 \mathrm{~cm}^{2}$, decay period: $0.7 \mathrm{se}-$ conds.

Table 2 shows the sorting accuracy of tomatoes by DLE. The sorting accuracies were 100, 94, 70 and 75 percent for color groups (1), (2), (3) and (4) respectively. The accuracy in groups (1) and (2) was very high compared with that in groups (3) and (4). In details, drift error of tomatoes from group (3) to group (2) was 5 percent, while the drift errors from group (3) to group (4) and from group (4) to group (3) were as high as 25 percent.

Thus, the color sorting accuracy of tomatoes by means of DLE was lower- 


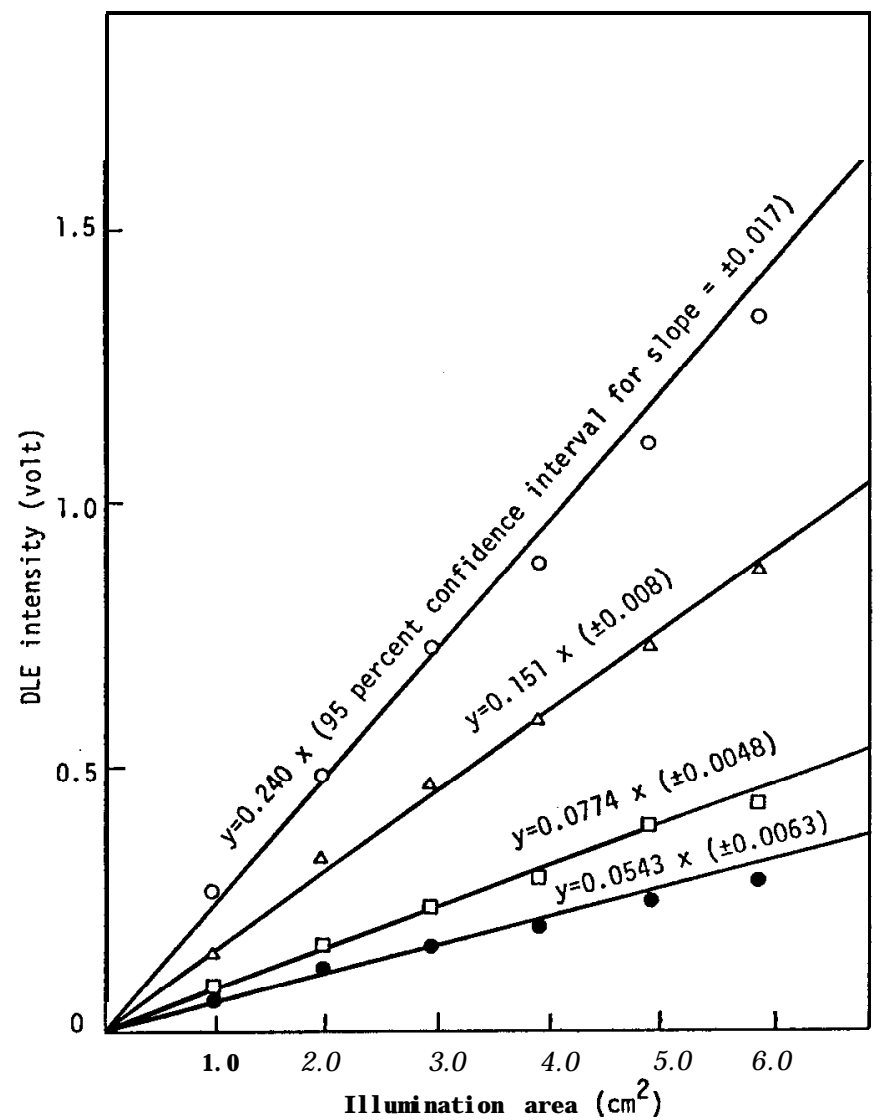

Fig. 6. Relation between illumination area and DLE intensity for green tomatoes. Conditions : dark period $10 \mathrm{~min}$, exciting illumination time $4 \mathrm{sec}$, illuminance $5,500 \mathrm{~lx}$. temperature $31^{\circ} \mathrm{C}$. $\bigcirc$ decay period $0.75 \mathrm{sec} . \triangle 1.0$ sec. $\square 1.5 \mathrm{sec}$,

$2.0 \mathrm{sec}$.

Table 2. Sorting accuracy of color group of tomatoes by means of DLE intensity. DLE intensity was measured in 0.7 sec decay period, 4 sec excitation time, 5,500 Ix illuminance, $9.07 \mathrm{~cm}^{2}$ excited area on tomato, 10 min dark period before excitation, and $13^{\circ} \mathrm{C}$ flesh temperature (volt).

\begin{tabular}{|c|c|c|c|c|}
\hline Color & group & $\begin{array}{c}\text { Range of } \\
\text { DLE intensities }\end{array}$ & $\begin{array}{l}\text { Sorting accuracy } \\
\text { of color group }\end{array}$ & Error \\
\hline & 1 & 1.50 and over & $100 \%$ & \\
\hline & 2 & 0.68 up to 1.50 & 94 & $5 \%($ to group 1$)$ \\
\hline & 3 & 0.23 up to 0.68 & 70 & $25 \begin{array}{ll}\text { (to group } & 2) \\
\text { (to group } 4)\end{array}$ \\
\hline & 4 & below 0.23 & 75 & (to group 3 ) \\
\hline
\end{tabular}

ed towards red groups (3) and (4) due to the low content of chlorophyll.

Tomatoes in the stage of groups (1) and (2) are shipped, and the sorting 


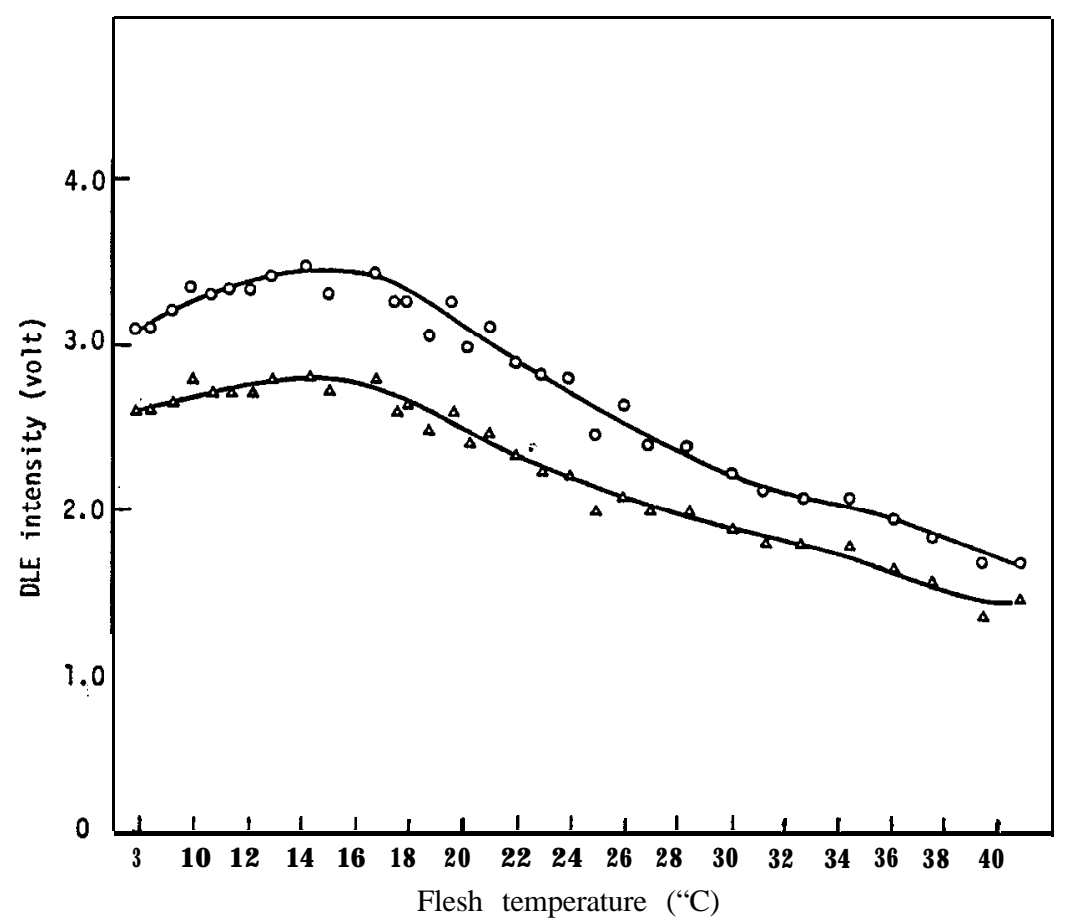

Fig. 7. Effect of flesh temperature on DLE intensity for green tomatoes. Conditions: dark period $10 \mathrm{~min}$, exciting illumination time $4 \mathrm{sec}$, illuminance $5,500 \mathrm{~lx}$, illumination area $9.07 \mathrm{~cm}^{2}$. $0.7 \mathrm{sec}$ decay period, $\triangle 0.8 \mathrm{sec}$.

accuracy is high in these groups.

\section{Effect of the thickness of tomato-flesh on DLE}

Effect of the thickness of tomato-flesh on DLE was investigated. Test samples of green and red tomatoes were prepared as specified in Fig. 9. The samples included, (1) a whole tomato, (2) a half tomato, (3) flesh thickness of $6 \mathrm{~mm}$ beneath the rind, the interior being scooped out, (4) the rind of tomato only, the inner flesh and tissue being hollowed out.

Fig. 9 shows the effect of the flesh-thickness on DLE intensity for green and red tomatoes. In case of green tomatoes, high intensity of delayed light was observed from the flesh less than $6 \mathrm{~mm}$ thickness beneath the rind. Beyond the thickness of outer flesh of $6 \mathrm{~mm}$, the thickness did not show any effect on the DLE intensity. In case of red ripe tomatoes, on the other hand, a trace of DLE appeared due to the small amount of chlorophyll still remaining in the inner tissue.

\section{DLE spectrum of tomatoes}

The DLE spectrum of tomatoes was investigated when excited by white light (tungsten lamp). Fig. 10 shows the synthetic results of the DLE corrected both with filter characteristics and relative sensitivity of photomulti- 


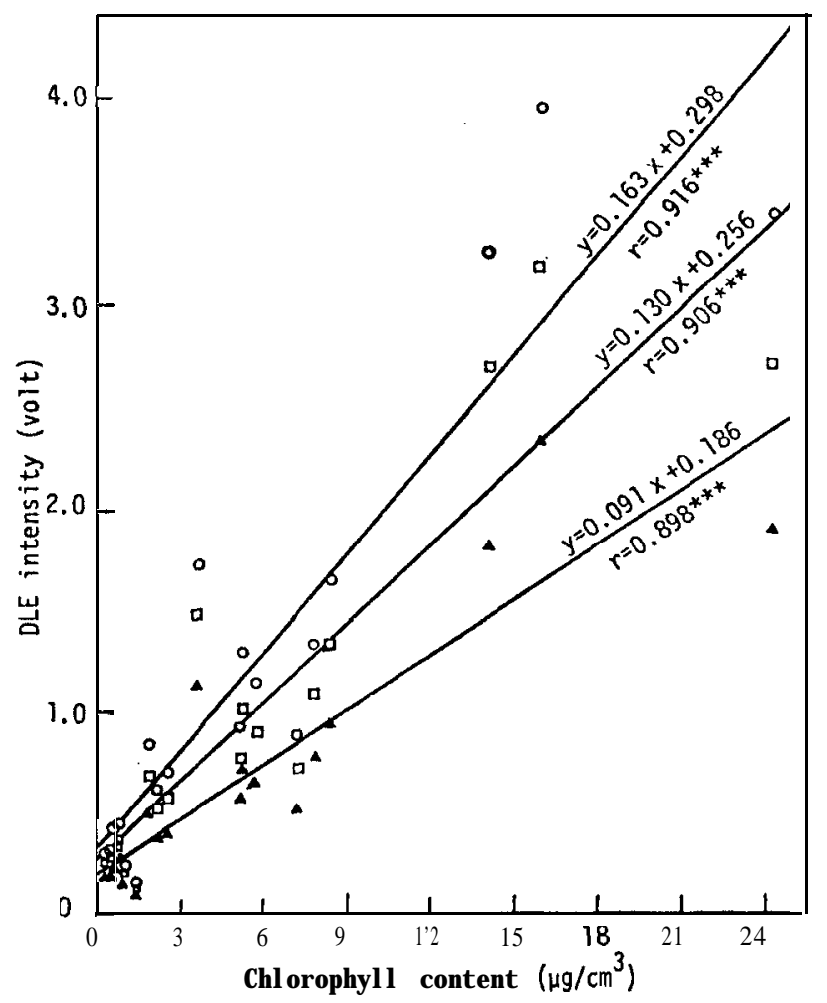

Fig. 8. Relation between chlorophyll content and DLE intensity for tomatoes. Conditions: dark period $10 \mathrm{~min}$, exciting illumination time 4 sec, illuminance 5,500 Ix. illumination area $9.07 \mathrm{~cm}^{2}$, temperature $13^{\circ} \mathrm{C}$. 0.7 sec decay period, $70.8 \mathrm{sec}, \triangle 1.0 \mathrm{sec}, y$ :DLE intensity, $x$ : chlorophyll content.

plier used. The DLE spectrum had a peak $695 \mathrm{~nm}$ and a bulge on the longer side of wavelength, and agreed well with the fluorescence spectrum of chlorophyll (Arnold and Davidson, 1954). From the result obtained, the photomultiplier having a high sensitivity at around $695 \mathrm{~nm}$ is recommendable for the DLE detector.

Sorting by the DLE eliminates the error due to the fluorescence which may occur in case of transmittance method as much as 25 percent of OD reading (Massie and Norris, 1975).

\section{CONCLUSIONS}

Factors influencing the intensity of delayed light emission (DLE) of tomatoes were investigated to obtain the basic data for the mechanical sorting, and the following results were obtained:

1. The relationship between dark period and DLE intensity was investi- 


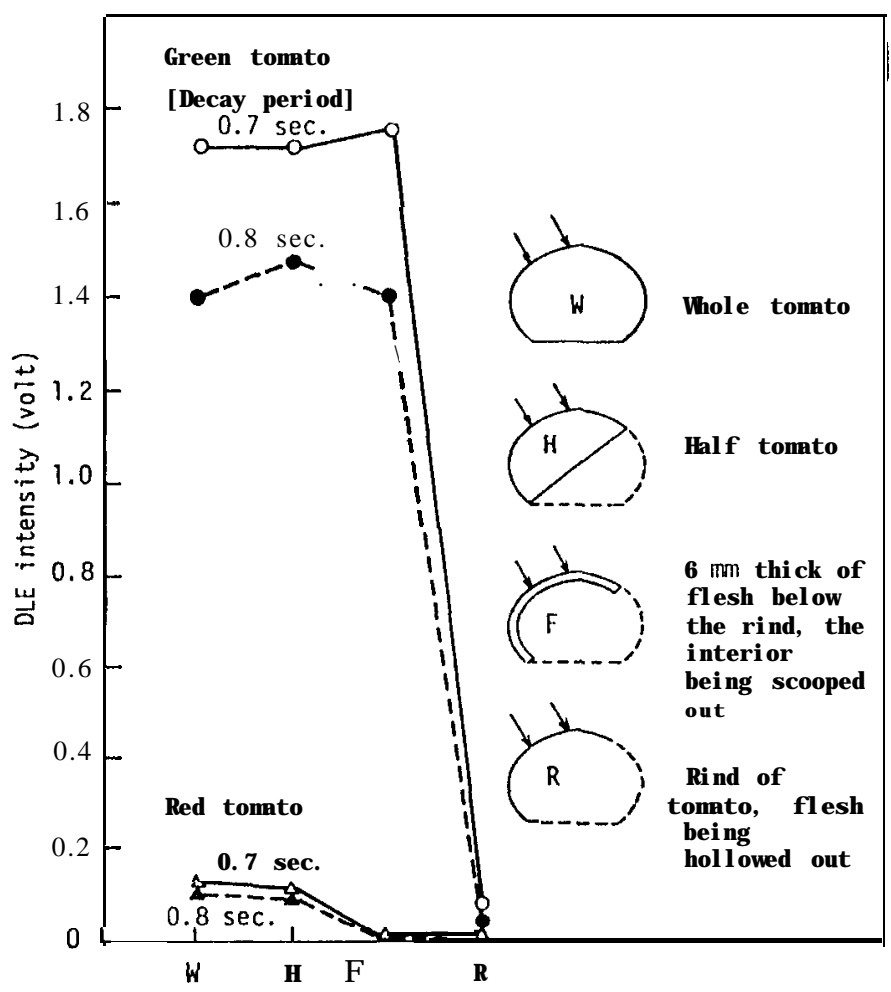

Fig. 9. Effect of the flesh-thick below the rind on DLE intensity for green and red tomatoes. Conditions: dark period $10 \mathrm{~min}$, exciting illumination time $4 \mathrm{sec}$, illuminance $5,500 \mathrm{~lx}$, illumination area $7.07 \mathrm{~cm}^{2}$, temperature $32^{\circ} \mathrm{C}$.

gated. Adequate working conditions were established as follows. Dark period for dark recovery of DLE: above 10 minutes and decay period: above 0.7 seconds.

2. Maximum DLE was obtained at the exciting time of 3 to 6 seconds by the exciting illuminance of $5,500 \mathrm{Ix}$.

3. Exciting illuminance needed for the DLE saturation increased towards the shorter 'decay period'. For the decay period of 1 second the illuminance for the saturation was $2,750 \mathrm{~lx}$.

4. The DLE intensity was directly proportional to the excitation area of tomatoes.

5. Maximum DLE intensity of tomatoes was obtained at the flesh temperature of 13 to $17^{\circ} \mathrm{C}$.

6. The relationship between the chlorophyll content and the DLE intensity was almost linear.

7. Color sorting accuracy of tomato was investigated by means of DLE. The green tomatoes were sorted with high accuracy, whereas red tomatoes 


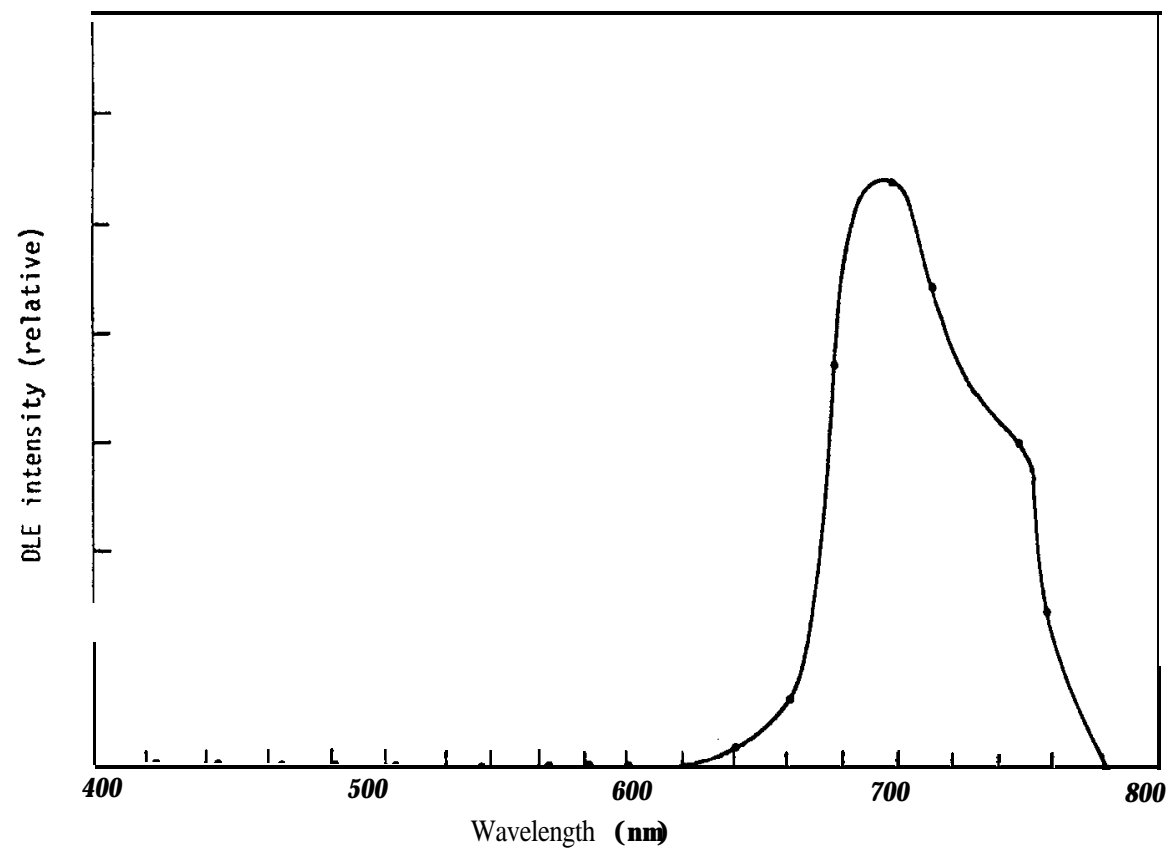

Fig. 10. DLE spectrum of tomatoes when excited by tungsten lamp (white light). Conditions: dark period $10 \mathrm{~min}$, exciting illumination time $4 \mathrm{sec}$. illuminance $5,500 \mathrm{~lx}$, temperature $13^{\circ} \mathrm{C}$, decay period $0.7 \mathrm{sec}$; green tomatoes.

could not be sorted with accuracy. The separation of green tomatoes from breaker' is of much importance from the point of practical application.

8. The relationship between the thickness of tomoto-flesh and the DLE intensity was investigated. Green ripe tomatoes emitted high delayed light from the flesh of $6 \mathrm{~mm}$ thick, which was the same level with that of a whole or a half tomato. In case of red ripe tomatoes a trace of DLE was observed which was not supposed to be influential on sorting accuracy.

9. The DLE spectrum of intact tomatoes had a peak at $695 \mathrm{~nm}$ and a bulge on the longer side of wavelength, and agreed well with the fluorescence spectrum of chlorophyll. Photomultiplier having a high sensitivity at around $695 \mathrm{~nm}$ is recommended as a DLE detector.

\section{REFERENCES}

Arnold, W. and J. B. Davidson 1954 The identity of the fluorescent and delayed light emission spectra. Jour. Gen. Physiol., 37: 677-664

ASHRAE 1971 ASHRAE Guide and Data Book. Applications. New York, pp. 392-393

1 The breaker has a small white or pink star at the blossom end and may be ripened several days' later. 
Chuma, Y., K. Sein, S. Kawano and K. Nakaji 1977 Delayed light emission as a means of automatic selection of Satsuma oranges. Trans. ASAE, 20(5): 99661000

Jacob, F. C., R. J. Romani and C. M. Sprock 1965 Fruit sorting by delayed light emission. Trans. $A S A E, E(1): 18-19.24$

Mackinney, G. 1941 Absorption of light by chlorophyll solutions. Jour.Biol.Chem., 140: 315-322

Massie, D. R. and K. H. Norris 1975 A high-intensity spectrophotometer interfaced with a computer for food quality measurement. Trans. $A S A E, 18(1)$ : 173-176

Strehler, B. L. and W. Arnold 1951 Light production by green plants. Jour. Gen. Physiol., $34: 809-820$ 